OPEN ACCESS

Edited by:

Rajan Singh,

Charles R. Drew University

of Medicine and Science,

United States

Reviewed by:

Egberto Gaspar Moura

Rio de Janeiro State University, Brazil

Zuhong $\mathrm{He}$,

Wuhan University, China

${ }^{*}$ Correspondence:

Saskia Braber

S.braber@uu.nl

tThese authors have contributed equally to this work

Specialty section:

This article was submitted to Molecular and Cellular Pathology,

a section of the journal

Frontiers in Cell and Developmental

Biology

Received: 15 March 2021

Accepted: 29 July 2021

Published: 16 August 2021

Citation:

Janbazacyabar $H$, van Daal $M$, Leusink-Muis T, van Ark I, Garssen J,

Folkerts G, van Bergenhenegouwen J and Braber $S$ (2021) The Effects

of Maternal Smoking on Pregnancy and Offspring: Possible Role for EGF?

Front. Cell Dev. Biol. 9:680902.

doi: 10.3389/fcell.2021.680902

\section{The Effects of Maternal Smoking on Pregnancy and Offspring: Possible Role for EGF?}

\author{
Hamed Janbazacyabar ${ }^{1}$, Marthe van Daal' ${ }^{1}$, Thea Leusink-Muis' ${ }^{1}$ Ingrid van Ark', \\ Johan Garssen ${ }^{1,2}$, Gert Folkerts ${ }^{1}$, Jeroen van Bergenhenegouwen ${ }^{1,2+}$ and \\ Saskia Braber ${ }^{*}{ }^{*}$
}

'Division of Pharmacology, Utrecht Institute for Pharmaceutical Sciences, Faculty of Science, Utrecht University, Utrecht, Netherlands, ${ }^{2}$ Danone Nutricia Research, Utrecht, Netherlands

Cigarette smoke exposure during pregnancy and lactation is associated with adverse pregnancy outcomes. Here, we investigated the effects of maternal smoke exposure on pregnancy and offspring immunity and explored whether, epidermal growth factor (EGF), an important growth-promoting factor in human colostrum and milk, might be a possible missing link in maternal smoke exposure and changes in infants' immune responses. Pregnant BALB/c mice were exposed to either cigarette smoke or air during gestation and lactation, and effects on pulmonary inflammation in dams and immune responses in offspring were examined. Maternal smoke exposure increased airway hyperresponsiveness and accumulation of inflammatory cells in the lungs of pregnant dams compared to non-pregnant dams. The E-cadherin protein expression was reduced in mammary glands of cigarette smoke-exposed pregnant dams. EGF levels were higher in mammary glands and serum of smoke-exposed pregnant dams compared to air-exposed pregnant dams. Offspring from cigarette smoke-exposed dams exhibited elevated levels of IL-17A, MCP-1, IL-22, and IL-13 in anti-CD3 stimulated spleen cell culture supernatants. EGF levels were also increased in serum of offspring from smoke-exposed dams. A positive correlation was observed between serum EGF levels and neutrophil numbers in bronchoalveolar lavage fluid of the dams. Interestingly, IL-17A, MCP-1, IL-22, IL13, and IFN- $\gamma$ levels in anti-CD3 stimulated spleen cell culture supernatants of male pups also showed a positive correlation with EGF serum levels. In summary, our results reveal that maternal smoke exposure predisposes dams to exacerbated airway inflammation and offspring to exacerbated immune responses and both phenomena are associated with elevated EGF concentrations.

Keywords: epidermal growth factor, pregnancy, airway hyper responsiveness, cigarette smoke, immune response, inflammation

\section{INTRODUCTION}

Smoking cigarettes throughout pregnancy is one of the most important preventable causes of adverse pregnancy outcomes (Hofhuis et al., 2003; Rauschert et al., 2019). Despite the well documented adverse health effects of maternal smoking and many efforts to reduce its prevalence, $20-30 \%$ of women who smoke, continue smoking during pregnancy and lactation 
(Dietz et al., 2010; Napierala et al., 2016). Besides active smoking, passive smoking (also known as environmental tobacco exposure (ETS) or second hand smoking) has also been linked to several diseases, including asthma and cancer. Because studies in nonsmokers have demonstrated that exposure to ETS is very common worldwide, ETS is also often used as a proxy for indoor air pollution (Gilmour et al., 2006). According to the World health Organization (WHO), over $80 \%$ of the world's 1.3 billion smokers live in low- and middle- income countries, and around 1.2 million deaths per year are attributable to ETS, worldwide. In addition, epidemiological studies have demonstrated high rates of ETS among the youth in these low- and middle-income countries (Wang et al., 2017; Elf et al., 2018). ETS contains the same range of tobacco smoke toxins as active smoking, therefore it is likely that ETS during pregnancy may also have important effects on fetal health. Maternal smoke exposure during pregnancy and lactation adversely affects birth weight (Bernstein et al., 2005), delivery time, fetal growth (Kolås et al., 2000; Fantuzzi et al., 2007), and immune development (Noakes et al., 2006). Cigarette smoke (CS) is an extremely complex and dynamic mixture containing more than 4000 harmful chemical compounds, (Bluhm et al., 1971; Ding et al., 2008). Especially, the smaller particles $(<1-5 \mu \mathrm{m})$ penetrate deeply into the lung tissue, crossing the lung barrier and reaching the blood circulation (Antonietta Gatti, 2015). Hence, in addition to the local pulmonary injury, CS has far-reaching consequences on systemic immune responses, directly causing alterations in the innate and adaptive host defense, such as elevated white blood cell counts, and increased C-reactive protein (CRP), interleukin (IL)-6, and fibrinogen levels (Bermudez et al., 2002; Sopori, 2002; Helmersson et al., 2005; Wannamethee et al., 2005; Mehta et al., 2008). Moreover, both in vivo and in vitro studies have shown that maternal smoking is associated with substantial changes in the placental morphology (Asmussen, 1977; Kawashima et al., 2014), which consequently lead to impairment of the placental barrier (Demir et al., 1994). Results even indicated that CS components with a low molecular weight and high water solubility can cross the placental barrier and cause fetal injury (Sabra et al., 2017).

In addition to the placental effect, cigarette smoking during pregnancy reduces basal prolactin levels leading to a decrease in milk supply (Greenberg et al., 1991; Primo et al., 2013), changes in milk composition and flavor (Hill and Aldag, 1996), and early weaning (Primo et al., 2013). Breast milk is a unique source of nutrition containing various macronutrients (carbohydrates, proteins, lipids, and vitamins), as well as numerous bioactive compounds (growth factors, hormones, cytokines, chemokines, and antimicrobial compounds) for newborn infants. Epidermal growth factor (EGF) is an important growth-promoting factor in human colostrum and milk and is suggested to be responsible for the protective effects of milk on the gastrointestinal tract (GI) of newborn infants (Dvorak et al., 2003). EGF exposure starts in fetal life, as during pregnancy, EGF concentrations gradually increase in amniotic fluid reaching the highest concentration toward the end of gestation (Dvorak, 2010). After parturition and in the postnatal period, maternal colostrum and milk are the main source of EGF for the newborn offspring (Dvorak, 2010). The first days after parturition, the human EGF levels are high and gradually decrease during the first 2 weeks of lactation (Moran et al., 1983; Dvorak, 2010).

Several studies have linked smoke exposure during pregnancy and lactation to an increased risk of immune related diseases in the offspring. However, literature on how smoke exposure during pregnancy and lactation affects the infant's immune system is scarce. The present study aims to investigate the effects of maternal CS-exposure on pregnancy and offspring immunity and to explore whether EGF might be a possible missing link in maternal smoke exposure and changes in infants' immune responses.

In this study, important lung parameters and EGF levels in serum and mammary gland were explored in pregnant and nonpregnant dams exposed to air or CS. In the offspring, sensitivity of splenic immune cells and serum EGF levels were investigated to determine whether correlations can be found between EGF and changes in the offspring's immune system.

\section{MATERIALS AND METHODS}

\section{Animals}

Sixty females and thirty males 8 -week-old specific pathogen free BALB/c by JIco mice were obtained from Charles River Laboratories (Someren, Netherlands). Upon arrival, mice were conventionally housed in groups (Female: 6/cage; Male: $5 /$ cage used for mating) in filter-topped makrolon cages $\left(22 \mathrm{~cm} \times 16 \mathrm{~cm} \times 14 \mathrm{~cm}\right.$, floor area $350 \mathrm{~cm}^{2}$, Tecnilab- BMI, Someren, Netherlands) with wood-chip bedding (Tecnilab- BMI, Someren in Netherlands) and tissues (VWR, Netherlands) were available as cage enrichment at the animal facility of Utrecht University. Animals were housed under a light/dark cycle of $12 \mathrm{~h} / 12 \mathrm{~h}$ (lights on from 7.00 am to $7.00 \mathrm{pm}$ ) at controlled relative humidity (relative humidity of 50-55\%) and temperature $\left(21 \pm 2^{\circ} \mathrm{C}\right)$ with ad libitum access to tap water and pelleted food (AIN-93G, Ssniff Spezialdiäten, Soest, Germany). After mating, cardboard houses were added to the cages. This study was conducted in accordance with institutional guidelines for the care and use of laboratory animals established by the Animal Ethics Committee of the Utrecht University, and all animal procedures related to the purpose of the research were approved under license of the national competent authority, securing full compliance the European Directive 2010/63/EU for the use of animals for scientific purposes.

\section{Mating, Gestation, and Smoke-Exposure}

After the acclimatization period (2 weeks) and one day prior to mating, female animals were randomly housed two per cage and assigned to the control $(n=30)$ or cigarette smoke (CS) exposure group $(n=30)$. The next day, a single male mouse was introduced to two females [considered as pregnancy day (P) 0]. After 4 days of mating, male mice were removed from the female cages. Afterward, from P4 until the end of lactation, the females were subjected to whole body exposure (pups remained in the cage with extra tissues to maintain temperature) in whole-body chambers (8 animals/chamber) to either air or diluted mainstream CS from the reference cigarettes 1R6F 
(University of Kentucky, Lexington, Kentucky) using smoke apparatus. Exposures were performed $45 \mathrm{~min} /$ day (resembling 14 cigarettes/day), 7 days/week, for 6 weeks (P4 until the end of lactation) (Zuo et al., 2014). Carbon monoxide (CO) levels was monitored continuously and was approximately 300-400 ppm. The mass concentration of cigarette smoke total particulate matter (TPM) was determined by gravimetric analysis using a type A/E glass fiber filter (PALL life sciences, Mexico). Briefly, the glass filter was weighed and placed in the filter holder. Next, CS was passed through the filter. TPM was calculated by subtracting the basal filter weight from the CS-exposed filter divided by the volume of the filter holder and expressed as $\mu \mathrm{g} / \mathrm{L}$ (Braber et al., 2012). The TPM concentration in the smoke exposure box generated by 14 cigarettes reached approximately $828 \mu \mathrm{g} / \mathrm{L}(828 \pm 4.5 \mu \mathrm{g} / \mathrm{L})$. At birth, the two mothers with their pups were maintained in filtered-top cages, and the numbers of viable offspring, along with the approximate duration of gestation, were determined. After 3 weeks of lactation, pups were weaned, sexed, and the sex ratio (male/female) and body weight were evaluated. After weaning, prenatally air and smoke-exposed pups were separately pooled and randomly assigned to the prenatal air or CS-exposure groups, analyzed for enhanced pause (Penh) and subsequently sacrificed ( $N=10 \mathrm{pups} / \mathrm{sex} /$ exposure group). An overview of the experimental design is presented in Supplementary Figure 1.

\section{Airway Responsiveness Measurement EMKA}

The EMKA invasive measurement of dynamic resistance (EMKA Technologies, Paris, France) in response to increasing doses of methacholine (acetyl- $\beta$-methyl-choline chloride, Sigma-Aldrich) $(0-25 \mathrm{mg} / \mathrm{mL}, 10 \%$ puff for $10 \mathrm{~s})$ was used to determine lung function of dams on day 21 of lactation (day 42 of the experiment) as performed previously (Verheijden et al., 2014). Mice were anesthetized by intraperitoneal injection of ketamine (Vetoquinol S.A., France; $125 \mathrm{mg} / \mathrm{kg}$ ) and medetomidine (Pfizer, Netherlands; $0.4 \mathrm{mg} / \mathrm{kg}$ ) mixture. Data are expressed as average lung resistance $(\mathrm{RL})$ in $\mathrm{cm} \mathrm{H} 2 \mathrm{O} / \mathrm{mL} \times \mathrm{sec}^{-1}$.

\section{Buxco}

The Forced Pulmonary Maneuver System (Buxco Electronics Inc., Wilmington, NC, United States) was used to determine lung function of pups at 21 days of age as performed previously (Verheijden et al., 2014) (x). The baseline measurements were recorded and averaged for $3 \mathrm{~min}$ after $5 \mathrm{~min}$ acclimatization of the animals to the full body plethysmograph flow (FWBP). Bronchial hyperreactivity was assessed using the Penh (enhanced pause) values and the area under the curve (AUC) as the indexes.

\section{Blood Sampling and Serum Preparation}

After measuring the lung function, dams and pups were euthanized using an overdose of pentobarbital by intra peritoneal injection (200 mg/kg; Nembutal ${ }^{\mathrm{TM}}$, Ceva Santé Animale, Naaldwijk, Netherlands). Animals were terminated via cardiac puncture and blood samples collected. The blood was then coagulated for $30 \mathrm{~min}$ at room temperature, centrifuged at
$8000 \times g$ for $10 \mathrm{~min}$, serum collected and stored at -20 until further analysis.

\section{Cotinine ELISA}

Cotinine measurement was performed in serum samples using the mouse/rat cotinine ELISA kit (Calbiotech, CA, United States) according to the manufacturer's instructions.

\section{Determination of Serum and Mammary Gland Homogenates EGF}

Serum levels of EGF were determined by using a Mouse EGF DuoSet ELISA (R\&D Systems, United States) according to the manufacturer's instructions.

\section{Bronchoalveolar Lavage}

After lung function measurement and immediately following euthanasia, a cannula was inserted into the trachea and lungs were lavaged four times with pre-warmed pyrogen-free saline $\left(0.9 \% \mathrm{NaCl}, 37^{\circ} \mathrm{C}\right)$ in situ ( $1 \mathrm{ml}$ for dams and $0.5 \mathrm{ml}$ for pups). Lungs were first lavaged with pyrogen-free saline $(0.9 \% \mathrm{NaCl}$, $37^{\circ} \mathrm{C}$ ) supplemented with protease inhibitor cocktail tablet (Complete Mini, Roche Diagnostics,Mannheim, Germany). This step was followed by three lavages with saline solution $(0.9 \%$ $\left.\mathrm{NaCl}, 37^{\circ} \mathrm{C}\right)$. The bronchioloalveolar lavage fluid was centrifuged at $4^{\circ} \mathrm{C}(400 \times \mathrm{g}, 5 \mathrm{~min})$ and the supernatant of the first lavage was used for cytokine measurement. Cell pellets from the four lavages were pooled per animal, resuspended in $150 \mu \mathrm{l}$ cold saline and counted under light microscopy using a Bürker-Türk chamber (magnification $100 \times$ ). Differential BALF cell counts were performed on air-dried cytospin preparations stained with DiffQuik $^{\mathrm{TM}}$ (Merz \& Dade A.G., Düdingen, Switzerland) and numbers of macrophages, neutrophils, eosinophils, and lymphocytes were identified according to standard morphology.

\section{Ex vivo Restimulation of Splenocytes}

Fresh spleens were collected aseptically and homogenized using the top of a syringe to gently pass through a $70 \mu \mathrm{m}$ nylon cell strainer. The collected cell suspension was washed and incubated with lysis buffer (Thermo Fisher, Netherlands), for $5 \mathrm{~min}$ to remove red blood cells. Splenocytes were washed and resuspended in RPMI 1640 medium (Lonza), supplemented with $10 \%$ heat-inactivated fetal bovine serum (FBS; Bodinco, Alkmaar, Netherlands), penicillin $(100 \mathrm{U} / \mathrm{mL}) /$ streptomycin $(100 \mu \mathrm{g} / \mathrm{mL}$; Sigma-Aldrich) and $\beta$-mercaptoethanol $(20 \mu \mathrm{M}$; Thermo Fisher Scientific). Total cell number was determined by using a Beckman Z1 coulter ${ }^{\circledR}$ Particle Counter (Beckman, United States) and splenocytes $\left(10^{7}\right.$ cells $\left./ \mathrm{ml}\right)$ were cultured in 96-well U-bottom plates (Greiner Bio-One B. V., Netherlands), either with medium or with $0.2 \mu \mathrm{g} / \mathrm{mL}$ anti-CD3 (Thermo Fisher, Netherlands). After 4 days stimulation, the supernatants were harvested and stored at $-20^{\circ} \mathrm{C}$ until further analysis. The concentrations of MCP-1, IL-17A, IL-13, IL-22, and IFN- $\gamma$ were measured using Beadbased immunoassays (Procartaplex, Thermo Fisher, Netherlands) according to the manufacturer's instructions. 


\section{Immunohistochemistry}

The colon was immersed and fixed in fresh $10 \%$ neutral buffered formalin for at least $24 \mathrm{~h}$ and embedded in paraffin as a "Swiss roll" (Moran et al., 1983) to permit a complete microscopic examination. After paraffin embedding, $5 \mu \mathrm{m}$ sections were cut. The sections were deparaffinized and endogenous peroxidase activity was blocked with $0.3 \% \mathrm{H} 2 \mathrm{O} 2$ (Merck, Darmstadt, Germany) in methanol for $30 \mathrm{~min}$ at room temperature and rehydrated in a graded ethanol series to PBS. For antigen retrieval, the slides were boiled in $10 \mathrm{mM}$ citrate buffer $(\mathrm{PH}$ 6.0) for $10 \mathrm{~min}$ in a microwave. The slides were cooled down to room temperature, rinsed with PBS $(3 \times)$ and blocked with $5 \%$ goat serum for $30 \mathrm{~min}$ at room temperature. Subsequently, sections were incubated with primary antibody rabbit anti-zonula occludens 1 (ZO-1) (Invitrogen) for $24 \mathrm{~h}$. Thereafter, sections were washed and incubated with Alexa Fluor 568-conjugated anti-rabbit IgG (ZF-0511; Zhongshan Biotechnology Co., Ltd., Beijing, China; diluted at 1:50 in PBS with 1\% BSA) for $1 \mathrm{~h}$ at RT. After washing, nuclear counterstaining was conducted using Hoechst (1:3000, Invitrogen) and sections were washed and mounted with ProLong Gold anti-fade reagent (Invitrogen). Immunofluorescence images were taken with Microscope Leica TCS SP8 X. Levels of laser intensity, confocal aperture, photomultiplier voltage, offset, scan speed, image size, filter, and magnification were equal for all images. Briefly, a minimum of four animals were selected per group and a minimum of four slides were stained for each animal. Afterward, confocal microscopic images were quantified for immunofluorescence intensity by ImageJ software (version: 1.52).

\section{Western Blot Analysis}

Approximately, $50 \mathrm{mg}$ of mammary gland specimens were lysed with $500 \mu$ l RIPA lysis buffer (Thermo scientific, Rockford, IL, United States) containing protease inhibitors (Roche Applied Science, Penzberg, Germany). Thereafter, total protein concentration was measured by a BCA protein assay kit (Thermo Scientific, Rockford, IL, United States). Standardized heat denaturized proteins were separated by electrophoresis (Criterion ${ }^{\mathrm{TM}}$ Gel, 4-20\% Tris-HCl, Bio-Rad Laboratories, Hercules, CA, United States) and transferred onto Trans-Blot Turbo Midi PVDF Transfer Packs (BioRad Laboratories, Hercules, CA, United States). Membranes were blocked using PBS supplemented with $0.05 \%$ Tween20 (PBST) and 5\% milk proteins. Thereafter, membranes were incubated with primary antibodies for mouse antiGAPDH (AM4300, Invitrogen, Carlsbad, CA, United States), mouse anti-E-cadherin (610182, eBioscience, San Diego, CA, United States) overnight at $4^{\circ} \mathrm{C}$, followed by incubation with rabbit anti-mouse Immunoglobulins secondary antibody, HRP conjugated (P026002-2, agilent, United States). Blots were washed and developed with ECL reagents mix (Amersham Biosciences, Roosendaal, Netherlands) and the digital images were obtained using ChemiDoc ${ }^{\text {TM }}$ XRS + System (Bio-Rad Laboratories, Hercules, CA, United States). All the blots were exposed at the same time using the same exposure time. The intensity of the bands was quantified with Image
Lab software (version 5.2, 2014, Bio-Rad Laboratories, Hercules, CA, United States) and normalized to anti-mouse GAPDH. Full uncut blots are included as Supplementary Data (Supplementary Figure 5).

\section{Statistical Analysis}

Unless stated otherwise, results are expressed as mean \pm standard error of mean (SEM). Data were statistically analyzed using a two-way ANOVA followed by a post hoc Bonferroni's multiple comparisons test. A probability value $P<0.05$ was considered significant. Statistical analyses were performed using GraphPad Prism software (version 6.04). The required sample size was calculated with $\mathrm{G}^{*}$ Power v3.1.9 based on a power of $80 \%$ and $\alpha=0,05$ and primary outcome parameter derived from previous observations of airway responsiveness which is the most relevant clinical parameter for CS-exposure.

\section{RESULTS}

\section{Effect of CS-Exposure on Pregnancy and Offspring}

Smoke exposure in pregnant mice induced a reduction in breeding success compared to air- exposed animals (Table 1). Although the mating period was 4 days, and the exact first day of pregnancy is not known, data seems to indicate that prenatal CS-exposure significantly increases the length of pregnancy (Table 1). CS-exposure during pregnancy reduced the litter size by $12.6 \%$ compared to the air-exposed group (Table 1), however, this difference did not reach statistical significance. No significant difference in the sex ratio of pups was observed between airand CS-exposed dams. Male and female pups from CS-exposed dams showed significantly lower body weight compared to pups from air-exposed dams. The spleen weight of pups from CSexposed dams was also reduced compared to the spleen weight of pups from air-exposed dams. However, this was only significantly different between prenatally smoke- and air-exposed female pups (Table 1).

\section{Increased Cotinine Concentration in the Serum of Dams After Cigarette Smoke Exposure}

Cotinine is the predominant metabolite of nicotine and is the most reliable biomarker to evaluate the level of smoke exposure. Cotinine concentrations were measured in the serum of air- and CS-exposed dams. Animals exposed to cigarette smoke during pregnancy and lactation showed a significantly higher cotinine level compared to air-exposed animals (Supplementary Figure 4).

\section{The AHR After Smoke Exposure Is More Obvious in Pregnant Dams Compared to Non-pregnant Dams}

To study the effect of CS-exposure during pregnancy and lactation on lung function, the AHR to methacholine 
TABLE 1 | Effect of CS-exposure on pregnancy and offspring.

Effect of CS smoke exposure on pregnancy and offspring

\begin{tabular}{|c|c|c|}
\hline & \multicolumn{2}{|c|}{ Experimental group } \\
\hline & Air & cs \\
\hline Duration of pregnancy ${ }^{a}$ & $21.53 \pm 0.27$ & $23 \pm 0.33^{\star \star}$ \\
\hline Litter size & 4.66 & 4.07 \\
\hline No. of pregnant dams ${ }^{b}$ & 15 & 13 \\
\hline Female/male ratio & 1.38 & 1.23 \\
\hline \multicolumn{3}{|c|}{ Body weight (offspring) ${ }^{c}$} \\
\hline Female & $10.56 \pm 0.175$ & $9.2 \pm 0.249^{\star}$ \\
\hline Male & $10.56 \pm 0.175$ & $9.7 \pm 0.3^{*}$ \\
\hline \multicolumn{3}{|c|}{ Spleen weight/body weight ratio ${ }^{d}$} \\
\hline Female & $0.0076 \pm 0.0003$ & $0.0062 \pm 0.0003^{*}$ \\
\hline Male & $0.0068 \pm 0.0004$ & $0.0058 \pm 0.0002$ \\
\hline $\begin{array}{l}{ }^{a} \text { Based on the first day } \\
\text { period was } 4 \text { days. } \\
{ }^{b} \text { Values represent the } m \\
{ }^{c} \text { Values represent the } m \\
{ }^{d} \text { Values represent the } m \\
{ }^{*} \text { Significantly different ( } p\end{array}$ & $\begin{array}{l}\text { sidered as gestation } \\
\text { nals/experimental gr } \\
10 \text { animals/experim } \\
\text { air-exposed group. } \\
\text { e air-exposed group }\end{array}$ & $\begin{array}{l}\text { day 0), the mating } \\
\text { p). } \\
\text { tal group). }\end{array}$ \\
\hline
\end{tabular}

was evaluated one day after the last CS-exposure. Lung resistance (LR), as a measure for AHR, was found to be significantly higher due to CS exposure in both pregnant (P) and non-pregnant mice (NP) (Figure 1A). When CSexposed pregnant animals were compared to non-pregnant animals, CS-exposure lead to a significant increased LR in pregnant animals. To increase our understanding of the smoke-induced effects on AHR, an area-under-curve (AUC) plot was generated, including all LR measurements (Figure 1B). AUC analysis indicates that CS significantly increased AHR in both non-pregnant and pregnant animals, while pregnant animals have significantly higher LR values compared to non-pregnant animals. Interestingly, pregnant animals were found to show higher AHR indicated by the significant difference between the air-exposed non-pregnant and pregnant animals.

\section{The Increase in Neutrophil Numbers in BALF After CS-Exposure Is More Obvious in Pregnant Dams Compared to Non-pregnant Dams}

To investigate the extent of airway inflammation after CS-exposure, cell numbers in BALF were determined (Figures 1C-F). CS-exposure, but not air-exposure, leads to an increase in total BALF cell counts, as well as the in numbers of neutrophils, lymphocytes, and macrophages. Although, both pregnant and non-pregnant dams showed an increase in neutrophil infiltration after CS-exposure, the neutrophil influx was significantly higher in CS-exposed pregnant dams compared to CS-exposed non-pregnant dams.

\section{No Obvious Changes in BALF Cell Counts of Pups After Prenatal CS-Exposure}

Pregnant and non-pregnant mice were exposed to either CS or air throughout pregnancy and lactation and adverse effects of prenatal CS-exposure on pulmonary function and inflammation were investigated in both female and male offspring. Due to the size of the pups, AHR was determined using the Forced Pulmonary Maneuver System as described in the method and materials and presented as an enhanced pause (Penh) value. AUC analysis indicates no significant difference between CS or air-exposed animals nor differences between the sexes (Supplementary Figure 2A). Upon BALF analysis, no significant differences were observed between prenatally CS- and airexposed offspring in total cell counts, neutrophil, lymphocyte and macrophage numbers (Supplementary Figure 2B-E).

\section{Prenatal CS-Exposure Increases Cytokine Production After ex vivo Re-stimulation of Spleen Cells From the Offspring}

To investigate whether maternal CS-exposure leads to changes in immunocompetence in the offspring, spleen cell suspensions were ex vivo re-stimulated with anti-CD3 antibody to investigate T-cells responses (Figures $\mathbf{2 A - E}$ ). In contrast to female offspring, maternal CS-exposure caused markedly elevated levels of IL17A, MCP-1, IL-22, and IL-13 in anti-CD3 stimulated spleen cell culture supernatants of male pups. No significant differences were detected between male and female offspring of air-exposed dams ( \pm CD3). IFN- $\gamma$ levels seemed to be increased following anti-CD3 stimulation in both females and males, however, this did not reach significance. Notably, cytokine expression in unstimulated spleen cell culture supernatants were either very low or absent and no significance differences were observed between the male and female offspring.

\section{Effect of CS-Exposure on EGF Levels in Dams and Offspring}

CS-exposure increased serum EGF levels in both non-pregnant and pregnant females compared to air-exposed animals, however, only in pregnant females this increase was found to be significant. No differences in EGF levels were observed between pregnant and non-pregnant air-exposed dams (Figure 3A). The EGF concentration in the mammary gland tissue homogenates of CS-exposed pregnant dams was also significantly higher than airexposed pregnant dams, while non-pregnant dams showed a very low EGF concentration in mammary gland tissue homogenates (Figure 3B). Non-pregnant dams did not show a significant increase in serum and mammary gland EGF levels after CSexposure. Interestingly, prenatal CS-exposure resulted in an increase in serum EGF levels of the offspring. However, this effect only reached significance in the male pups (Figure 3C).

We hypothesized that pregnancy would induce dam EGF levels in the serum to the same extent as in the mammary glands. Indeed, a significant correlation was observed with higher 
A

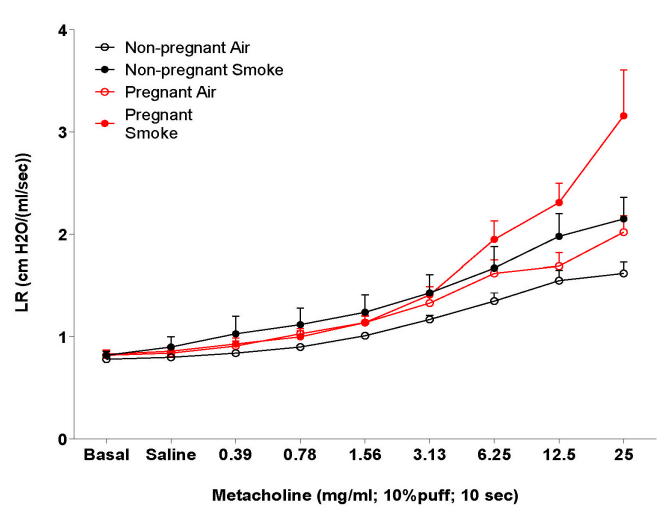

C

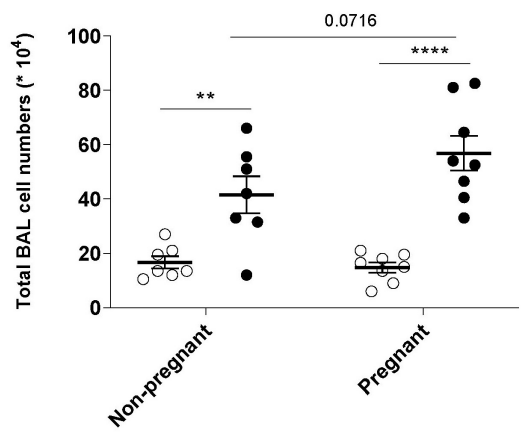

$\mathbf{E}$

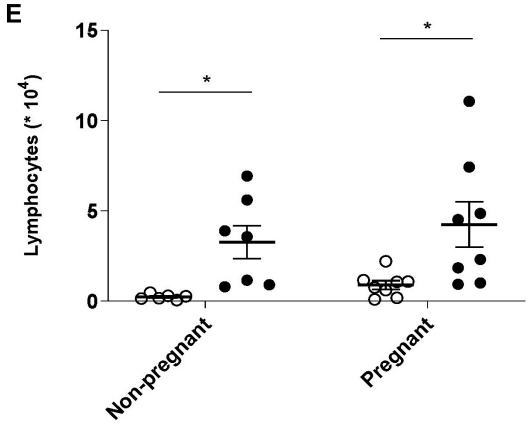

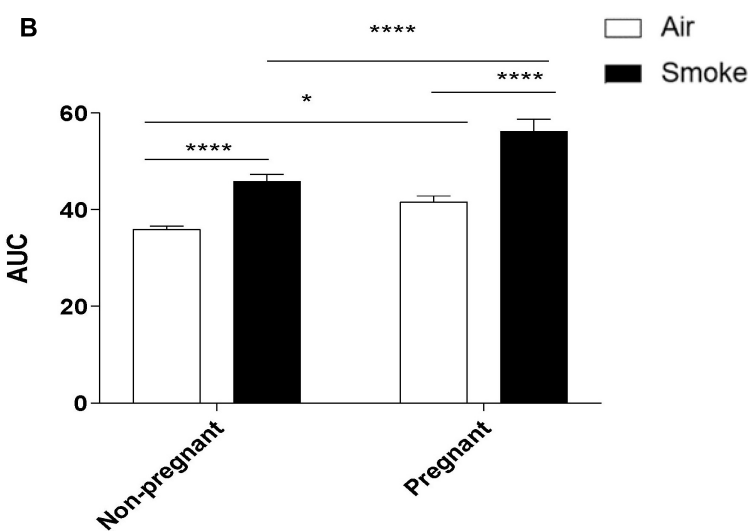

D

o Air

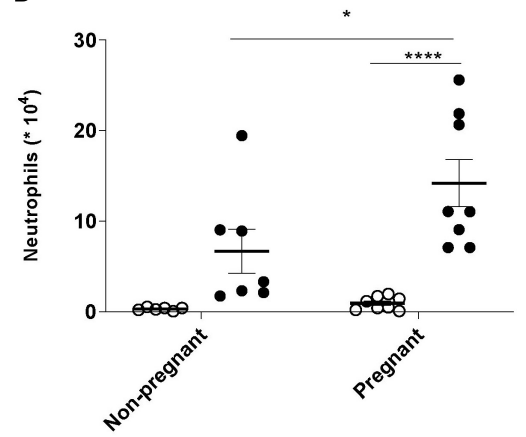

- Smoke

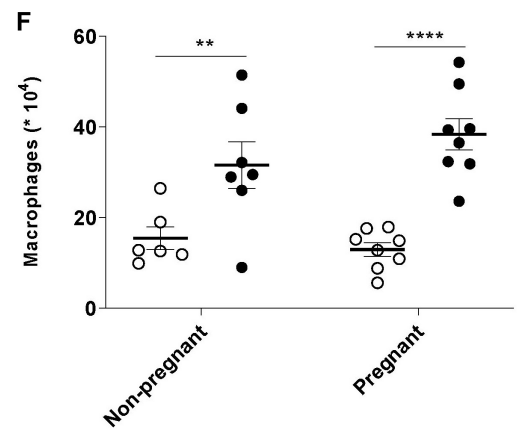

FIGURE 1 | The increase in neutrophil numbers in BALF and AHR after smoke exposure is more obvious in pregnant dams compared to non-pregnant dams. Pregnant and non-pregnant animals were exposed to air/smoke during pregnancy and lactation and animals were sacrificed at the end of lactation. Lung resistance (RL) was measured after exposure to increasing doses of methacholine (A). Areas-Under-Curve (AUC) were calculated for statistical analysis as mean $\pm \mathrm{SEM}$ (B). Lungs were lavaged and BALF was collected for total (C) and differential BAL cell counts, including neutrophils (D), Lymphocytes (E), and macrophages (F). ${ }^{\star} P<0.05,{ }^{*} P<0.01$, and ${ }^{* \star * *} P<0.0001$; as analyzed by two-way ANOVA followed by Bonferroni's multiple comparisons test, $N=7$ (Non-pregnant; air-exposed). $N=7$ (Non-pregnant; CS-exposed). $N=10$ (Pregnant; air-exposed). $N=10$ (Pregnant; CS-exposed).

serum levels correlating with higher EGF level of mammary gland tissue, depicted in Figure 4A. Next, it was investigated whether serum EGF levels could be related to inflammatory BALF cell numbers. Analyzing serum EGF levels and BALF neutrophil numbers of pregnant animals, a significant correlation was found (Figure 4B). In the offspring we hypothesized that serum EGF levels might impact on spleen cytokine production. In support of this hypothesis, a positive correlation between serum EGF levels and levels of IL-17A, MCP-1, IL-13, and IFN- $\gamma$, but not IL-22 in CD3 stimulated spleen supernatants was observed (Figures 4C-G, respectively).

\section{CS-Exposure During Pregnancy and Lactation Reduced E-Cadherin Protein Expression in Mammary Gland of Pregnant Dams Compared to Air-Exposed Pregnant Dams}

To evaluate the effect of CS-exposure during pregnancy and lactation on the blood-milk barrier, protein expression of E-cadherin was measured in mammary gland tissue. Results indicated that the protein expression of E-cadherin was significantly reduced in mammary gland of CS-exposed pregnant 

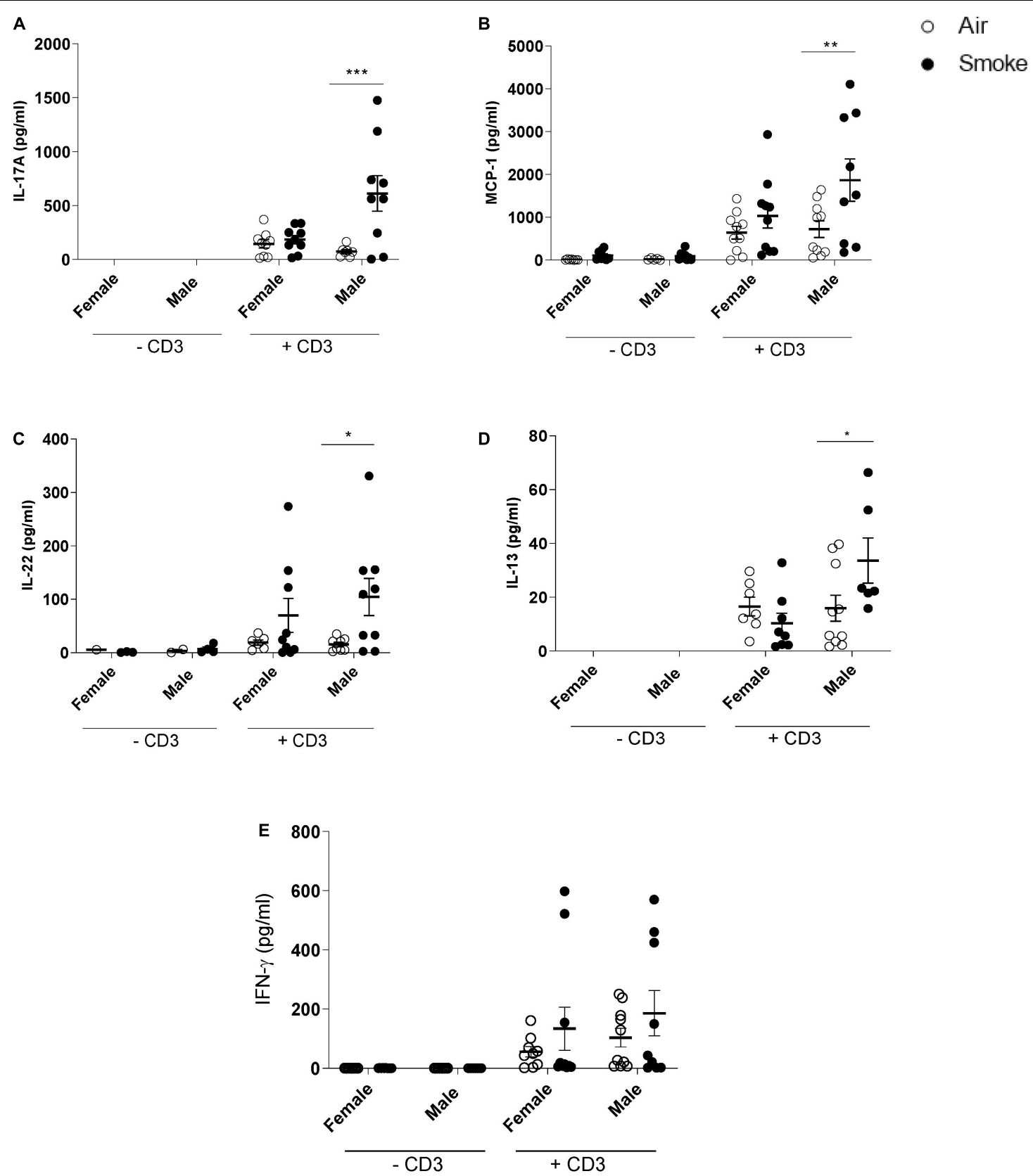

FIGURE 2 | Prenatal CS-exposure increases cytokine production after ex vivo re-stimulation of spleen cells from the offspring. Prenatally air- and CS-exposed offspring were sacrificed at the end of lactation. (A) IL-17A, (B) MCP-1, (C) IL-22, (D) IL-13, and (E) IFN- $\gamma$ concentrations were measured in supernatant after ex vivo stimulation of splenocytes with CD3 for 4 days $\left(37^{\circ} \mathrm{C}, 5 \%\right.$ CO2). Data are presented as mean \pm SEM. ${ }^{\star} P<0.05$, ${ }^{\star *} P<0.01,{ }^{\star \star} P<0.001$, as analyzed by two-way ANOVA followed by Bonferroni's multiple comparisons test ( $n=8-10 /$ group).

dams compared to air-exposed dams (Figure 5). As expected, there was no E-cadherin protein expression in mammary gland tissue of non-pregnant dams.

\section{DISCUSSION}

Although cigarette smoking during pregnancy and lactation has been linked to several adverse pregnancy outcomes, smoking during pregnancy is still a prevalent behavior in many countries (Lange et al., 2018; Kondracki, 2019). In addition to active smoking, passive smoking (second hand smoke exposure) has been shown to have a high prevalence in low- and middleincome countries (Elf et al., 2018). Long-term direct and indirect CS-exposure (ETS, second hand smoking) causes a wide range of damaging health effects, including increased lung inflammation, protease activity, oxidant stress, and apoptosis (Gopal et al., 2016). To the best of our knowledge, there is no 


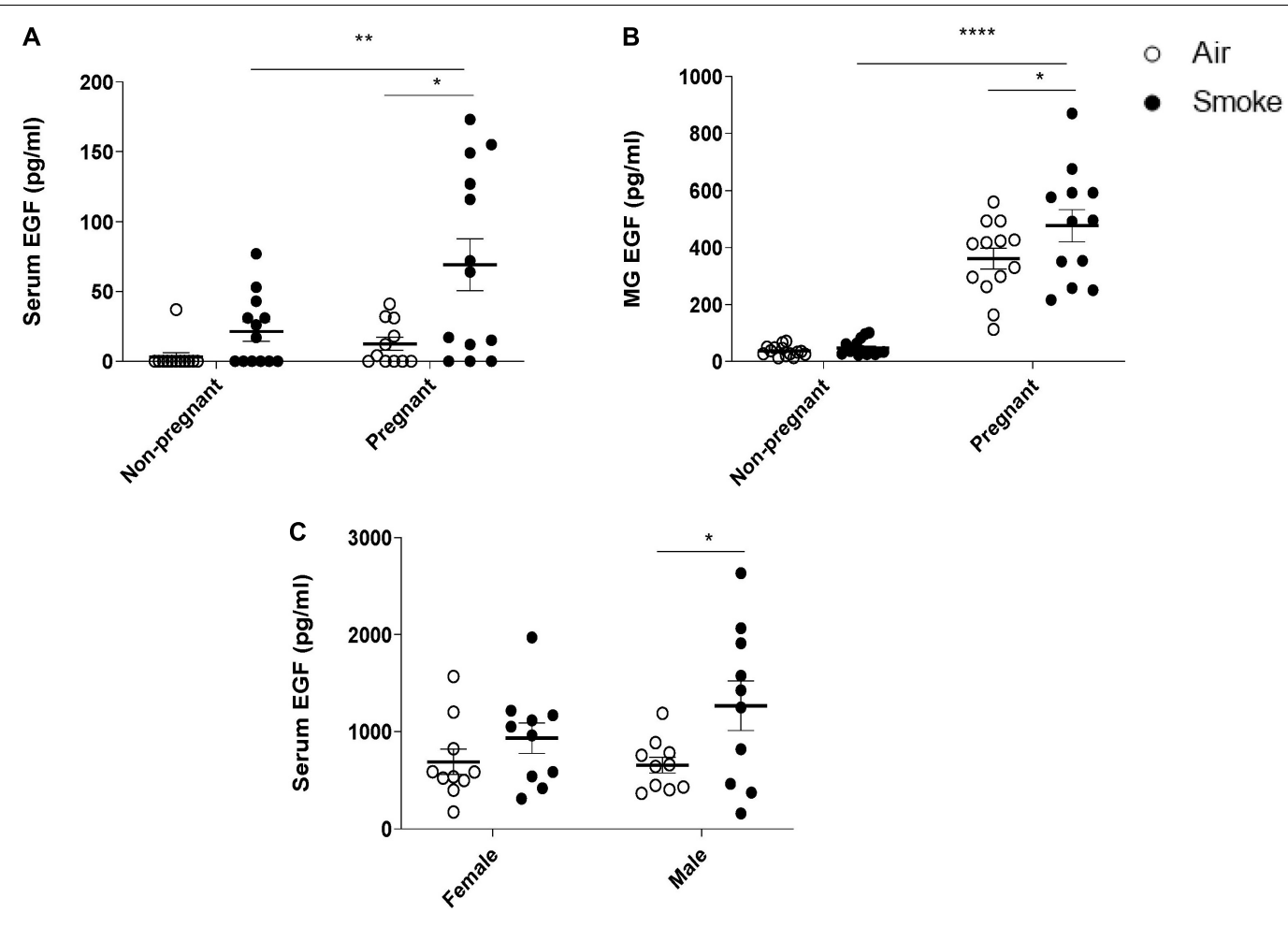

FIGURE 3 | Effect of CS-exposure on EGF levels in dams and offspring. EGF concentrations were measured in (A) serum of dams, (B) mammary gland (MG) tissue homogenates, and $(\mathbf{C})$ serum of offspring. Data are presented mean \pm SEM. ${ }^{\star} P<0.05$, ${ }^{\star \star} P<0.01$, and, ${ }^{\star \star \star \star} P<0.0001$, as analyzed by two-way ANOVA followed by Bonferroni's multiple comparisons test ( $n=10-15$ mice/group).

literature available examining the effect of maternal smoking on susceptibility to lung injury during pregnancy. Hence, this is the first article describing the adverse effects of maternal smoke exposure on AHR and the accumulation of inflammatory cells in the lungs of pregnant dams compared to non-pregnant mice. To have a level of exposure relevant to the human situation, we surveyed the literature for the correlation between cotinine levels and reported smoking behavior listed as light and heavy smokers (Jalili et al., 1998; Blackford et al., 2006; Xu et al., 2014). Unfortunately, the heterogeneity of reported cotinine levels and its association with smoking behavior between studies prevented us to qualify our reported cotinine levels (Supplementary Figure 4) as light or heavy smoking. However, based on TPM measurements, our total exposure is in line with previous similar in vivo experiments (Braber et al., 2012).

In the current study, non-pregnant mice exposed to CS showed a significant increase in the number of inflammatory cells in BALF, including neutrophils, lymphocytes, and macrophages, which is also observed by other authors (D'hulst et al., 2005; Martorana et al., 2005; Braber et al., 2010). Although the mean linear intercept $(\mathrm{Lm})$, a measure of alveolar size/damage, was not determined in this 6-week study, other studies showed that cigarette smoke exposure for several weeks did not induce significant differences in $\mathrm{Lm}$ values in non-pregnant mice (Hartney et al., 2012; Rinaldi et al., 2012). Consistent with the findings observed in the BALF, airway responsiveness upon methacholine exposure in CS-exposed non-pregnant mice was significantly increased when compared to non-pregnant airexposed mice. Interestingly, the CS-exposed pregnant animals showed a larger increase in AHR upon methacholine exposure compared to non-pregnant CS-exposed animals. The underlying mechanism on how CS exposure leads to increased AHR during pregnancy and lactation is not defined yet. However, several studies have indicated the link between neutrophil infiltration and AHR (Lukacs et al., 1996; Koga et al., 2013; Gao et al., 2017). AHR is a characteristic of many inflammatory lung diseases, and it has also been associated with chronic inflammation and infiltration of inflammatory cells, such as neutrophils (Vestbo and Hansen, 2001). Excessive infiltration and activation of neutrophils leads to the production and release of granule proteins, including serine proteases, matrix metalloproteinases, and myeloperoxidase. These factors contribute to the bronchial inflammation and induce structural changes, subsequent altered airway function and inflammatory processes via the induction of chemokine release by airway epithelial cells (Gernez et al., 2010; Koga et al., 2013; Victoni et al., 2016). Hence, a possible explanation for increased AHR is the link between pregnancy and higher neutrophil recruitment into the lungs. Pregnancy is associated with an increased number of white blood cells (Abbassi-Ghanavati et al., 2009). In healthy pregnant women, higher levels of peripheral blood granulocytes and a higher activation of peripheral blood leukocytes is detected compared with non-pregnant women (Sacks et al., 1998; Luppi et al., 2002; Harita et al., 2012). In addition, an elevated expression of 


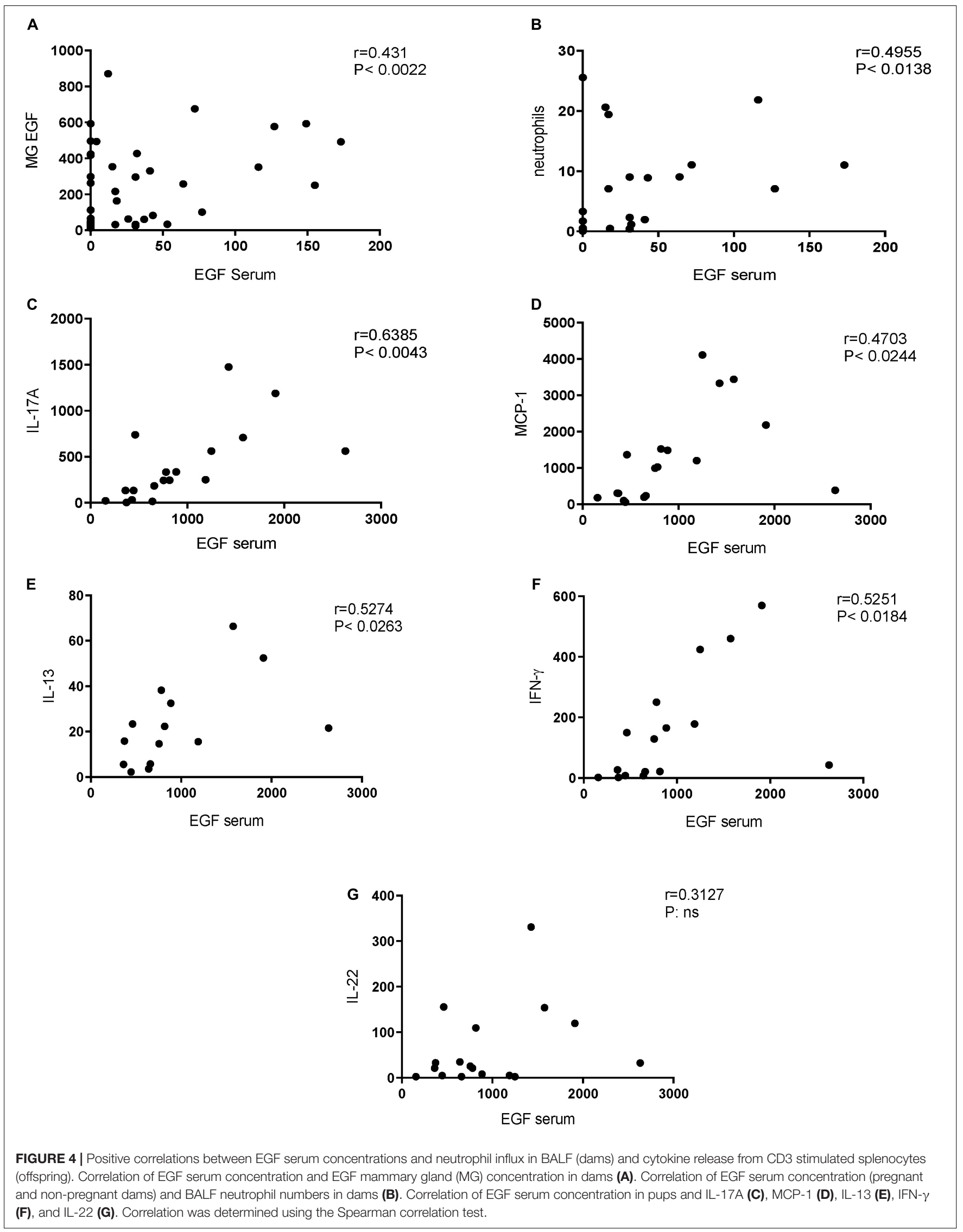




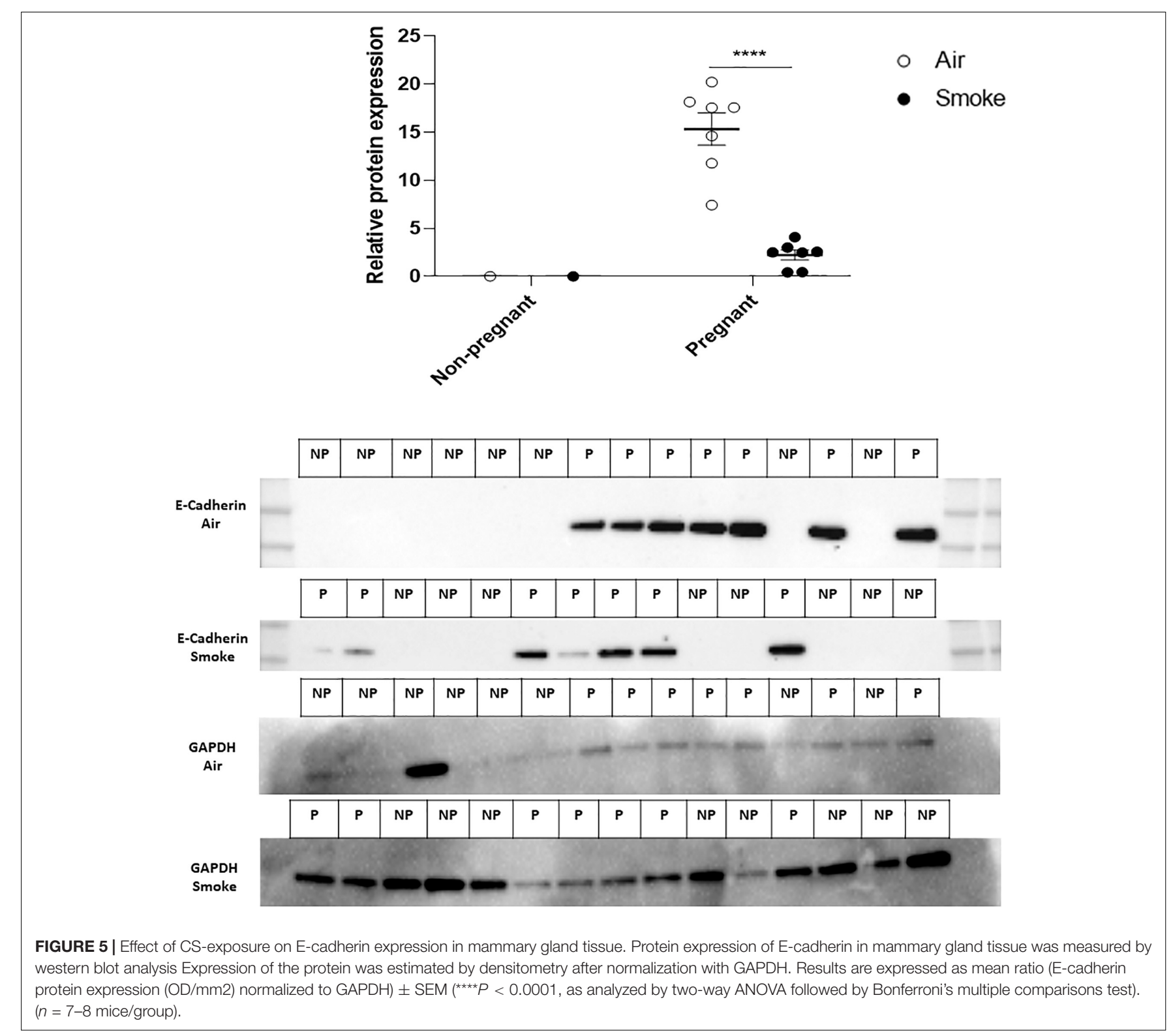

surface adhesion molecules on granulocytes and granulocyte basal intracellular reactive oxygen species are observed in pregnant women. An in vitro study has highlighted the effect of pregnancy on neutrophil activation and neutrophil-endothelial interaction namely, exposure of neutrophils to conditioned medium from normal placental cultures stimulates neutrophil activation and neutrophil adhesion to endothelial cells (Wang et al., 2001). Enhancement of circulatory neutrophils and increased expression of surface adhesion markers, such as selectins, can lead to higher neutrophil recruitment into the lung. Here, we demonstrated, that maternal CS-exposure significantly increased the neutrophil number in the BALF of pregnant mice compared to non-pregnant animals. Overall, the findings from our study indicate that the response to CS-exposure in pregnant mice is different compared to non-pregnant mice as observed by a higher number of neutrophils in the BALF and increased AHR.
This is an important finding and paves the way for future human studies to validate these observations.

Although various animal models have been used to investigate the association of neutrophil accumulation with the development of severe lung diseases, the underlying molecular mechanisms of neutrophil accumulation in the airways remain poorly understood. Several studies provided evidence that growth factors, such as EGF play an important role in neutrophil infiltration into the lung. CS induces EGF expression in ciliated cells of the airway epithelium and EGF up-regulation is observed in airway epithelium of smokers in association with airway dysfunction (Le Cras et al., 2010; Shaykhiev et al., 2013). We demonstrate that CS-exposed pregnant dams have significantly higher serum EGF levels compared to non-pregnant CS-exposed dams, and these higher levels positively correlate with neutrophil numbers in BALF of dams. EGF enhances the 
ex vivo production of chemotactic factors by the epithelial cells and its hypersecretion is associated with airway wall remodeling and lung inflammation (Shim et al., 2001; Hamilton et al., 2003; Holgate, 2011). An in vitro study, using the bronchial $16 \mathrm{HBE}$ cell line and primary bronchial epithelial cells from healthy individuals, indicated that exposure to EGF enhances neutrophil accumulation via stimulation of pro-inflammatory cytokines and chemokines (Uddin et al., 2013). A clinical study showed that EGF induces a significant up-regulation of proneutrophilic factors, like IL-6, IL-8, GM-CSF, and TNF- $\alpha$ in asthmatic patients. Overall, this would suggest that high serum EGF levels during pregnancy potentially sensitize an individual to environmental-induced lung injury mediated through increased accumulation and activation of innate cells. Besides EGF, several studies have shown that hormonal fluctuations could also lead to significant changes in lung function, including AHR (Carey et al., 2007; Card and Zeldin, 2009). For instance, estrogen receptor$\alpha$ knockout mice exhibited lung function abnormalities and increased airway responsiveness to inhaled methacholine under basal conditions (Carey et al., 2007). However, these findings await clinical validation where the relation between EGF and susceptibility to lung injury needs to be further researched.

Apart from these effects of CS-exposure on dams, results from different in vivo studies indicate that prenatal CS-exposure can also lead to altered immune responses in the offspring. In the present study, we observed that prenatal CS-exposure leads to markedly elevated IL-13, IL-22, and IL-17A in antiCD3 stimulated spleen cell culture supernatants of 3-week-old male pups. These cytokines play an influential role in inducing allergic reactions. For instance, prenatal allergen-specific Th-2 responses, particularly IL-13 responses, have been associated with atopic risk or subsequent allergic diseases (Gabrielsson et al., 2001; Kopp et al., 2001; Spinozzi et al., 2001). Moreover, it has been reported that serum levels of IL-22 are higher in patients with severe asthma than those seen healthy control subjects (Zhao et al., 2010). The pro-inflammatory properties of IL-22 are demonstrated as IL-22 is detected at the sites of allergic airway inflammation (Takahashi et al., 2011). IL-17 plays a critical role in allergic responses and autoimmune inflammation (Wang and Liu, 2008; Eun-Hyung Lee et al., 2010; Robinson et al., 2013). The increased level of the IL-17 and IL-22 directly correlates with increased disease severity (i.e., increased AHR). We further showed that prenatal smoke exposure significantly increases the MCP-1 secretion by splenocytes followed by anti-CD3 stimulation. MCP-1, as monocyte chemoattractant protein, is associated with the development of polarized Th2 responses (Deshmane et al., 2009). Additionally, MCP-1 induces polarization of Th0 cells toward a Th2 phenotype ( $\mathrm{Gu}$ et al., 2000). Overall, the increased level of all cytokines/chemokines released by anti-CD3 stimulated splenocytes of prenatal CSexposed male pups might be indicators for a predisposition toward Th2 responses. Indeed, prenatal CS-exposure has been linked with augmented Th2 differentiation along with enhanced Th2-type cytokine production, a known contributor to allergic inflammation (Murata et al., 2002; Noakes et al., 2003). Some studies have revealed that CS-exposure during pregnancy will raise the risk of asthma in the offspring (Zacharasiewicz, 2016;
Huang et al., 2017). Huang et al. (2017) reported that early life CSexposure aggravates OVA-induced asthma, airway inflammation, and increased infiltration of neutrophils, eosinophils, and other inflammatory cells.

Growth factors affect a wide variety of physiological processes including cell proliferation, differentiation and immunological responses. However, the abnormal production or regulation of growth factors can lead to development of various diseases, such as cancers and bronchopulmonary dysplasia (Sporn and Roberts, 1986; Thébaud and Abman, 2007). EGF is absent from commercially available infant formulas and preclinical data indicate that supplementation of formula with EGF supports growth, maturation and function of the gastroenteral tract (GI) (O'Loughlin et al., 1985; Berseth, 1987; Opleta-Madsen et al., 1991). The epidermal growth factor family has been known for its ability to stimulate cell proliferation and deregulation of the members of EGF family and their receptors has been shown to be closely associated with inflammatory diseases, such as atherosclerosis (Zeboudj et al., 2018). We observed that the concentration of EGF in the mammary gland tissue homogenates of CS-exposed pregnant dams was significantly higher than air-exposed pregnant dams and this increase was positively correlated with serum EGF levels. Moreover, prenatally exposed pups also demonstrated higher serum EGF levels. Blood-milk barrier disruption would be a candidate for factors eliciting higher EGF levels in mammary gland tissue homogenates. Supporting this, our results indicate that maternal smoke exposure reduced the E-cadherin expression in the mammary gland tissue, which is known as an adherence junction protein. E-cadherin has been identified as a primary classical cadherin in luminal epithelial cells and plays a crucial role in mammary gland differentiation and cell survival of alveoli in the lactating gland (Boussadia et al., 2002; Shamir and Ewald, 2015). Boussadia et al. (2002) showed that E-cadherin mutant mouse were not able to lactate and the differentiation of the mammary alveolar epithelium was affected in these mice. Several studies have noted the role of CS exposure in the downregulation of adherence junctions in lung tissue (Xi et al., 2000; Di Vincenzo et al., 2019). An in vitro study using an air-liquid interface system with human primary airway epithelial cells showed that smoke exposure is associated with reduced E-cadherin expression (Nishida et al., 2017). Besides the local effect of smoke exposure, results from different in vivo studies indicate that CS can affect other organs as well. Interestingly, a mouse model of CS-exposure presented a disturbed intestinal integrity as observed by reduction in ZO-1 expression in the small intestine (Zuo et al., 2014). In addition, CS-exposure causes intestinal barrier dysfunction of the small bowel with increased intestinal permeability and bacterial translocation in a murine smoke exposure model (Zuo et al., 2014). These effects might contribute to the increased serum EGF level observed in our prenatally CSexposed pups. In addition, using an immunofluorescent staining, we found that there is a tendency toward a reduction in ZO-1 expression in the colon tissue of parentally CS-exposed male pups (Supplementary Figure 3). This suggest that CS exposure can exert several deleterious effects on the intestinal barrier, which might result in higher absorption of EGF into the circulation. 
In the current study, we have demonstrated a strong positive correlation between the serum EGF levels and IL-17A, MCP-1, IL-13, IFN- $\gamma$ levels in anti-CD3 stimulated spleen cell culture supernatants of 3-week-old male pups. EGF promotes cell growth and differentiation by binding to its receptor, the epidermal growth factor receptor (EGFR) EGFR (Harris et al., 2003; Dvorak, 2010). Binding of EGF to the EGFR extracellular domain (EGFRECD) promotes its inactive-to-active conformational transition (activation), but the relevant detailed mechanism remains still elusive. EGFR is a transmembrane protein, which controls major signaling pathways, including cell survival, proliferation, and migration. Human and experimental studies have shown that an increased expression of EGFR by autocrine ligand stimulation leads to dysregulation of the downstream signaling system, which consequently results in a range of pathophysiological disorders such as cancer development (Zeboudj et al., 2018). Splenic CD4 + T cells and human blood T cells express EGFR, especially in response to CD3 (Zeboudj et al., 2018). EGFR signaling is crucial in CD4 $+\mathrm{T}$ cell homeostasis in both humans and mice and this role was further proved by epidemiological findings where patients treated with EGFR inhibitors might be particularly susceptible to infections (Burtness et al., 2012; Minutti et al., 2017). Moreover, inhibition of EGFR leads to a significant reduction of in vitro and in vivo cell proliferation and Th1/Th2/Th17 cytokine production. Moreover, smoke exposure induces EGFR phosphorylation and activation in different tissues (Filosto et al., 2012), which consequently leads to overproduction of cytokines (Paul et al., 2014). The strong correlation between EGF levels and cytokines measured in the spleen cultures strongly indicate a role for EGF as an immunomodulator. However, other than EGF, components such as nicotine have also been shown to have immunomodulating properties and capable of reducing mitogen-induced splenic T-cell proliferation (Kalra et al., 2004). It is of relevance to study a role for nicotine in these effects because nicotine has been found in the breastmilk of smoking mothers and cotinine could be detected in the urine of infants born to smoking mothers, suggesting systemic availability of nicotine and nicotine metabolites (Mascola et al., 1998; Amir, 2001). In support of our findings, it was previously shown that activation of EGF by EGF-specific ligands increased mast cell chemotactic protein transcription by dental follicle cells, indicating direct immune effects following EGF activation (Liu et al., 2008). It is of relevance to study the contribution of EGF in relation nicotine for their effect on splenic restimulations to further delineate a possible EGF specific effect. Future studies should then include naive mouse splenic restimulations in the absence or presence of nicotine, nicotine metabolites or EGF.

Previous studies have highlighted the role of sex difference in adaptive immune responses. For instance, it has been shown that male rats (early in life) have a larger thymus and a higher thymocyte count compared to female rats (Leposavić et al., 1996; Leposavić et al., 2011). In addition, clinical studies have demonstrated that natural killer cell frequencies are higher in male compared to female children (Lee et al., 1996). In the current study, prenatally CS-exposed male offspring showed higher immune responses to CD3 stimulation compared to female animals. This finding is in agreement with previous data of Casimir et al. (2010), who found that human infant males have higher pro-inflammatory responses compared to females following stimulation with LPS. The findings that male offspring are more vulnerable than the female to maternal smoke exposure is supported by recent studies (Stevenson et al., 2000; Kirchengast and Hartmann, 2009; Murphy et al., 2012; Miyake et al., 2013; Roy et al., 2014; Owili et al., 2018). Other studies on different outcomes also indicate that males are more susceptible to develop insulin resistance, obesity, adverse lung outcomes, and dyslipidemia (Shahid et al., 2008; Ng et al., 2009; Wang et al., 2020).

Despite the known detrimental effect of smoke exposure during pregnancy and lactation, in the European Union, 10-27\% of the pregnant women who smoke continue smoking during pregnancy. This study is the first to indicate that mothers who smoke during pregnancy and lactation may be at greater risk of developing lung injuries. We showed that CS-exposure during pregnancy and lactation significantly increases the airway hyperresponsiveness and neutrophil infiltration into lung of dams compared to non-pregnant dams. In addition, we have demonstrated that prenatal and postnatal CS-exposure alters the immune responses in the offspring. Spleen cells isolated from prenatally CS-exposed animals showed higher sensitivity to CD3 stimulation compared to the air-exposed group. Moreover, in the current study we have indicated that EGF might be a possible missing link in maternal CS-exposure and infant's immune hypersensitivity. However, further research is needed to elucidate the mechanisms by which prenatal and postnatal CS-exposure leads to higher immune responses.

\section{DATA AVAILABILITY STATEMENT}

The original contributions presented in the study are included in the article/ Supplementary Material, further inquiries can be directed to the corresponding author.

\section{ETHICS STATEMENT}

The animal study was reviewed and approved by Dierexperimentencommissie Utrecht.

\section{AUTHOR CONTRIBUTIONS}

SB, HJ, JB, JG, and GF designed research. HJ, MD, TL-M, and IA performed research. HJ and TL-M analyzed data. HJ, GF, JB, and $\mathrm{SB}$ wrote the manuscript. All authors contributed to the article and approved the submitted version.

\section{SUPPLEMENTARY MATERIAL}

The Supplementary Material for this article can be found online at: https://www.frontiersin.org/articles/10.3389/fcell.2021. 680902/full\#supplementary-material 


\section{REFERENCES}

Abbassi-Ghanavati, M., Greer, L. G., and Cunningham, F. G. (2009). Pregnancy and laboratory studies: a reference table for clinicians. Obstet. Gynecol. 114, 1326-1331. doi: 10.1097/AOG.0b013e3181c2bde8

Amir, L. H. (2001). Maternal smoking and reduced duration of breastfeeding: a review of possible mechanisms. Early Hum. Dev. 64, 45-67. doi: 10.1016/s03783782(01)00170-0

Antonietta Gatti, S. M. (2015). Case studies in nanotoxicology and particle toxicology. 1st ed. Cambridge, MA: Academic Press.

Asmussen, I. (1977). Ultrastructure of the human placenta at term. Observations on placentas from newborn children of smoking and non-smoking mothers. Acta Obstet. Gynecol. Scand. 56, 119-126. doi: 10.3109/00016347709158 353

Bermudez, E. A., Rifai, N., Buring, J. E., Manson, J. E., and Ridker, P. M. (2002). Relation between markers of systemic vascular inflammation and smoking in women. Am. J. Cardiol. 89, 1117-1119. doi: 10.1016/s0002-9149(02)02284-1

Bernstein, I. M., Mongeon, J. A., Badger, G. J., Solomon, L., Heil, S. H., and Higgins, S. T. (2005). Maternal smoking and its association with birth weight. Obstet. Gynecol. 106, 986-991. doi: 10.1097/01.AOG.0000182580.78402.d2

Berseth, C. L. (1987). Enhancement of intestinal growth in neonatal rats by epidermal growth factor in milk. Am. J. Physiol. Liver Physiol. 253, G662-G665. doi: 10.1152/ajpgi.1987.253.5.G662

Blackford, A. L., Yang, G., Hernandez-Avila, M., Przewozniak, K., Zatonski, W., Figueiredo, V., et al. (2006). Cotinine concentration in smokers from different countries: relationship with amount smoked and cigarette type. Am. Soc. Prev. Oncol. 15, 1799-1804. doi: 10.1158/1055-9965.EPI-06-0427

Bluhm, A. L., Weinstein, J., and Sousa, J. A. (1971). Free radicals in tobacco smoke. Nature 229, 500. doi: 10.1038/229500a0

Boussadia, O., Kutsch, S., Hierholzer, A., Delmas, V., and Kemler, R. E. - (2002). cadherin is a survival factor for the lactating mouse mammary gland. Mech. Dev. 115, 53-62. doi: 10.1016/s0925-4773(02)00090-4

Braber, S., Henricks, P. A. J., Nijkamp, F. P., Kraneveld, A. D., and Folkerts, G. (2010). Inflammatory changes in the airways of mice caused by cigarette smoke exposure are only partially reversed after smoking cessation. Respir. Res. 11:99. doi: 10.1186/1465-9921-11-99

Braber, S., Thio, M., Blokhuis, B. R., Henricks, P. A. J., Koelink, P. J., Groot Kormelink, T., et al. (2012). An association between neutrophils and immunoglobulin free light chains in the pathogenesis of chronic obstructive pulmonary disease. Am. J. Respir. Crit. Care Med. 185, 817-824. doi: 10.1164/ rccm.201104-0761OC

Burtness, B., Marur, S., Bauman, J. E., Golemis, E. A., Mehra, R., and Cohen, S. J. (2012). Comment on "epidermal growth factor receptor is essential for toll-like receptor 3 signaling”. Sci. Signal 5:lc5. doi: 10.1126/scisignal.2003734

Card, J. W., and Zeldin, D. C. (2009). Hormonal influences on lung function and response to environmental agents: lessons from animal models of respiratory disease. Proc. Am. Thorac. Soc. 6, 588-595. doi: 10.1513/pats.200904-020RM

Carey, M. A., Card, J. W., Bradbury, J. A., Moorman, M. P., Haykal-Coates, N., Gavett, S. H., et al. (2007). Spontaneous airway hyperresponsiveness in estrogen receptor-alpha-deficient mice. Am. J. Respir. Crit. Care Med. 175, 126-135. doi: 10.1164/rccm.200509-1493OC

Casimir, G. J. A., Heldenbergh, F., Hanssens, L., Mulier, S., Heinrichs, C., Lefevre, N., et al. (2010). Gender differences and inflammation: an in vitro model of blood cells stimulation in prepubescent children. J. Inflamm. 7:28. doi: 10.1186/ 1476-9255-7-28

Demir, R., Demir, A. Y., and Yinanc, M. (1994). Structural changes in placental barrier of smoking mother. A quantitative and ultrastructural study. Pathol. Res. Pract. 190, 656-667. doi: 10.1016/s0344-0338(11)80744-2

Deshmane, S. L., Kremlev, S., Amini, S., and Sawaya, B. E. (2009). Monocyte chemoattractant protein-1 (MCP-1): an overview. J. Int. Soc. Interf. Cytokine Res. 29, 313-326. doi: 10.1089/jir.2008.0027

D’hulst, A. I., Vermaelen, K. Y., Brusselle, G. G., Joos, G. F., and Pauwels, R. A. (2005). Time course of cigarette smoke-induced pulmonary inflammation in mice. Eur. Respir. J. 26, 204-213. doi: 10.1183/09031936.05.00095204

Di Vincenzo, S., Sangiorgi, C., Ferraro, M., Gjomarkaj, M., Ninaber, D. K., Hiemstra, P. S., et al. (2019). Cigarette smoke decreases E-Cadherin expression downregulating FoxO3 in lung epithelial cells. Eur. Respir. J. 54:A1678. doi: 10.1183/13993003.congress-2019.PA1678
Dietz, P. M., Homa, D., England, L. J., Burley, K., Tong, V. T., Dube, S. R., et al. (2010). Estimates of Nondisclosure of Cigarette Smoking Among Pregnant and Nonpregnant Women of Reproductive Age in the United States. Am. J. Epidemiol. 173, 355-359. doi: 10.1093/aje/kwq381

Ding, Y. S., Zhang, L., Jain, R. B., Jain, N., Wang, R. Y., Ashley, D. L., et al. (2008). Levels of tobacco-specific nitrosamines and polycyclic aromatic hydrocarbons in mainstream smoke from different tobacco varieties. Am. Soc. Prev. Oncol. 17, 3366-3371. doi: 10.1158/1055-9965.EPI-08-0320

Dvorak, B. (2010). Milk epidermal growth factor and gut protection. J. Pediatr. 156, S31-S35. doi: 10.1016/j.jpeds.2009.11.018

Dvorak, B., Fituch, C. C., Williams, C. S., Hurst, N. M., and Schanler, R. J. (2003). Increased Epidermal Growth Factor Levels in Human Milk of Mothers with Extremely Premature Infants. Pediatr. Res. 54, 15-19. doi: 10.1203/01.PDR. 0000065729.74325 .71

Elf, J. L., Kinikar, A., Khadse, S., Mave, V., Gupte, N., Kulkarni, V., et al. (2018). Secondhand Smoke Exposure and Validity of Self-Report in Low-Income Women and Children in India. Pediatrics 141, S118-S129. doi: 10.1542/peds. 2017-10260

Eun-Hyung Lee, F., Georas, S. N., and Beck, L. A. (2010). IL-17: Important for Host Defense, Autoimmunity, and Allergy? J. Invest. Dermatol. 130, 2540-2542. doi: 10.1038/jid.2010.295

Fantuzzi, G., Aggazzotti, G., Righi, E., Facchinetti, F., Bertucci, E., Kanitz, S., et al. (2007). Preterm delivery and exposure to active and passive smoking during pregnancy: a case-control study from Italy. Paediatr. Perinat. Epidemiol. 21, 194-200. doi: 10.1111/j.1365-3016.2007.00815.x

Filosto, S., Becker, C. R., and Goldkorn, T. (2012). Cigarette smoke induces aberrant EGF receptor activation that mediates lung cancer development and resistance to tyrosine kinase inhibitors. Mol. Cancer Ther. 11, 795-804. doi: 10.1158/1535-7163.MCT-11-0698

Gabrielsson, S., Söderlund, A., Nilsson, C., Lilja, G., Nordlund, M., and TroyeBlomberg, M. (2001). Influence of atopic heredity on IL- 4-, IL-12- and IFNgamma-producing cells in in vitro activated cord blood mononuclear cells. Clin. Exp. Immunol. 126, 390-396. doi: 10.1046/j.1365-2249.2001.01703.x

Gao, H., Ying, S., and Dai, Y. (2017). Pathological Roles of Neutrophil-Mediated Inflammation in Asthma and Its Potential for Therapy as a Target. J. Immunol. Res. 2017:3743048. doi: 10.1155/2017/3743048

Gernez, Y., Tirouvanziam, R., and Chanez, P. (2010). Neutrophils in chronic inflammatory airway diseases: can we target them and how? Eur. Respir. J. 35, 467-469. doi: 10.1183/09031936.00186109

Gilmour, M. I., Jaakkola, M. S., London, S. J., Nel, A. E., and Rogers, C. A. (2006). How exposure to environmental tobacco smoke, outdoor air pollutants, and increased pollen burdens influences the incidence of asthma. Environ. Health Perspect. 114, 627-633. doi: 10.1289/ehp.8380

Gopal, S. H., Mukherjee, S., and Das, S. K. (2016). Direct and Second Hand Cigarette Smoke Exposure and Development of Childhood Asthma. J. Environ. Heal. Sci. 2:1122. doi: 10.15436/2378-6841.16.1122

Greenberg, R. A., Bauman, K. E., Strecher, V. J., Keyes, L. L., Glover, L. H., Haley, N. J., et al. (1991). Passive smoking during the first year of life. Am. J. Public Health 81, 850-853. doi: 10.2105/ajph.81.7.850

Gu, L., Tseng, S., Horner, R. M., Tam, C., Loda, M., and Rollins, B. J. (2000). Control of TH2 polarization by the chemokine monocyte chemoattractant protein-1. Nature 404, 407-411. doi: 10.1038/35006097

Hamilton, L. M., Torres-Lozano, C., Puddicombe, S. M., Richter, A., Kimber, I., Dearman, R. J., et al. (2003). The role of the epidermal growth factor receptor in sustaining neutrophil inflammation in severe asthma. Clin. Exp. Allergy 33, 233-240. doi: 10.1046/j.1365-2222.2003.01593.x

Harita, N., Kariya, M., Hayashi, T., Sato, K. K., Nakamura, K., Endo, G., et al. (2012). Increment of absolute neutrophil count in the third trimester and increased risk of small-for-gestational-age birth: Hirakata Risk Associated with Pregnancy Assessment Research (HIRAPAR). Eur. J. Obstet. Gynecol. Reprod. Biol. 164, 30-34. doi: 10.1016/j.ejogrb.2012.05.039

Harris, R. C., Chung, E., and Coffey, R. J. E. G. F. (2003). receptor ligands. Exp. Cell Res. 284, 2-13. doi: 10.1016/s0014-4827(02)00105-2

Hartney, J. M., Chu, H., Pelanda, R., and Torres, R. M. (2012). Sub-chronic exposure to second hand smoke induces airspace leukocyte infiltration and decreased lung elastance. Front. Physiol. 3:300. doi: 10.3389/fphys.2012.00300

Helmersson, J., Larsson, A., Vessby, B., and Basu, S. (2005). Active smoking and a history of smoking are associated with enhanced prostaglandin $\mathrm{F}$ (2alpha), 
interleukin-6 and F2-isoprostane formation in elderly men. Atherosclerosis 181, 201-207. doi: 10.1016/j.atherosclerosis.2004.11.026

Hill, P. D., and Aldag, J. C. (1996). Smoking and breastfeeding status. Res. Nurs. Health 19, 125-132. doi: 10.1002/(SICI)1098-240X(199604)19:2<125:: AID-NUR4<3.0.CO;2-O

Hofhuis, W., de Jongste, J. C., and Merkus, P. J. F. M. (2003). Adverse health effects of prenatal and postnatal tobacco smoke exposure on children. Arch. Dis. Child 88, 1086-1090. doi: 10.1136/adc.88.12.1086

Holgate, S. T. (2011). The sentinel role of the airway epithelium in asthma pathogenesis. Immunol. Rev. 242, 205-219. doi: 10.1111/j.1600-065X.2011. 01030.x

Huang, F., Cheng, H., Zhang, Y., Ju, Y., and Li, Y. (2017). Early Postnatal Exposure to Cigarette Smoke Leads to Later Airway Inflammation in Asthmatic Mice. PLoS One 12:e0171021. doi: 10.1371/journal.pone.0171021

Jalili, T., Murthy, G. G., and Schiestl, R. H. (1998). Cigarette smoke induces DNA deletions in the mouse embryo. Cancer Res. 58, 2633-2638.

Kalra, R., Singh, S. P., Pena-Philippides, J. C., Langley, R. J., Razani-Boroujerdi, S., and Sopori, M. L. (2004). Immunosuppressive and anti-inflammatory effects of nicotine administered by patch in an animal model. Clin. Diagn. Lab. Immunol. 11, 563-568. doi: 10.1128/CDLI.11.3.563-568.2004

Kawashima, A., Koide, K., Ventura, W., Hori, K., Takenaka, S., Maruyama, D., et al. (2014). Effects of maternal smoking on the placental expression of genes related to angiogenesis and apoptosis during the first trimester. PLoS One 9:e106140-e106140. doi: 10.1371/journal.pone.0106140

Kirchengast, S., and Hartmann, B. (2009). The Male Disadvantage Hypothesis Reconsidered: Is There Really a Weaker Sex? An Analysis of Gender Differences in Newborn Somatometrics and Vital Parameters. J. Life Sci. 1, 63-71. doi: 10.1080/09751270.2009.11885136

Koga, H., Miyahara, N., Fuchimoto, Y., Ikeda, G., Waseda, K., Ono, K., et al. (2013). Inhibition of neutrophil elastase attenuates airway hyperresponsiveness and inflammation in a mouse model of secondary allergen challenge: neutrophil elastase inhibition attenuates allergic airway responses. Respir. Res. 14:8. doi: 10.1186/1465-9921-14-8

Kolås, T., Nakling, J., and Salvesen, K. A. (2000). Smoking during pregnancy increases the risk of preterm births among parous women. Acta Obstet. Gynecol. Scand. 79, 644-648. doi: 10.1111/j.1471-0528.1996.tb09877.x

Kondracki, A. J. (2019). Prevalence and patterns of cigarette smoking before and during early and late pregnancy according to maternal characteristics: the first national data based on the 2003 birth certificate revision. United States, 2016. Reprod Health 16:142. doi: 10.1186/s12978-019-0807-5

Kopp, M. V., Zehle, C., Pichler, J., Szépfalusi, Z., Moseler, M., Deichmann, K., et al. (2001). Allergen-specific T cell reactivity in cord blood: the influence of maternal cytokine production. Clin. Exp. Allergy J. Br. Soc. Allergy Clin. Immunol. 31, 1536-1543. doi: 10.1046/j.1365-2222.2001.01198.x

Lange, S., Probst, C., Rehm, J., and Popova, S. (2018). National, regional, and global prevalence of smoking during pregnancy in the general population: a systematic review and meta-analysis. Lancet Glob. Heal. 6, e769-e776. doi: 10.1016/S2214109X(18)30223-7

Le Cras, T. D., Acciani, T. H., Mushaben, E. M., Kramer, E. L., Pastura, P. A., Hardie, W. D., et al. (2010). Epithelial EGF receptor signaling mediates airway hyperreactivity and remodeling in a mouse model of chronic asthma. Am. J. Physiol. Cell Mol. Physiol. 300, L414-L421. doi: 10.1152/ajplung.00346.2010

Lee, B. W., Yap, H. K., Chew, F. T., Quah, T. C., Prabhakaran, K., Chan, G. S., et al. (1996). Age- and sex-related changes in lymphocyte subpopulations of healthy Asian subjects: from birth to adulthood. Cytometry 26, 8-15. doi: 10 . 1002/(SICI)1097-0320(19960315)26:1<8::AID-CYTO2<3.0.CO;2-E

Leposavić, G., Karapetrović, B., Obradović, S., Vidiíc Dandović, B., and Kosec, D. (1996). Differential effects of gonadectomy on the thymocyte phenotypic profile in male and female rats. Pharmacol. Biochem. Behav. 54, 269-276. doi: 10.1016/0091-3057(95)02165-5

Leposavić, G., Pilipović, I., and Perišić, M. (2011). Cellular and nerve fibre catecholaminergic thymic network: steroid hormone dependent activity. Physiol. Res. 60(Suppl. 1), S71-S82. doi: 10.33549/physiolres.932175

Liu, Z.-X., Wang, J., Yu, L., Tang, K.-L., Wang, X., and Li, S. (2008). Effect of epidermal growth factor on transcription of MCP-1 in rat dental follicle cells. Shanghai Kou Qiang Yi Xue 17, 212-215.

Lukacs, N. W., Lamm, W. J., Strieter, R. M., and Albert, R. K. (1996). Airway hyperreactivity is associated with specific leukocyte subset infiltration in a mouse model of allergic airway inflammation. Pathobiology 64, 308-313. doi: $10.1159 / 000164065$

Luppi, P., Haluszczak, C., Trucco, M., and Deloia, J. A. (2002). Normal pregnancy is associated with peripheral leukocyte activation. Am. J. Reprod. Immunol. 47, 72-81. doi: 10.1034/j.1600-0897.2002.10041.x

Martorana, P. A., Beume, R., Lucattelli, M., Wollin, L., and Lungarella, G. (2005). Roflumilast fully prevents emphysema in mice chronically exposed to cigarette smoke. Am. J. Respir. Crit. Care Med. 172, 848-853. doi: 10.1164/rccm.2004111549OC

Mascola, M. A., Van Vunakis, H., Tager, I. B., Speizer, F. E., and Hanrahan, J. P. (1998). Exposure of young infants to environmental tobacco smoke: breastfeeding among smoking mothers. Am. J. Public Health 88, 893-896. doi: 10. 2105/ajph.88.6.893

Mehta, H., Nazzal, K., and Sadikot, R. T. (2008). Cigarette smoking and innate immunity. Inflamm. Res. Off. J. Eur. Histamine Res. Soc. 57, 497-503. doi: 10.1007/s00011-008-8078-6

Minutti, C. M., Drube, S., Blair, N., Schwartz, C., McCrae, J. C., McKenzie, A. N., et al. (2017). Epidermal Growth Factor Receptor Expression Licenses Type2 Helper $\mathrm{T}$ Cells to Function in a $\mathrm{T}$ Cell Receptor-Independent Fashion. Immunity 47, 710.e-722.e. doi: 10.1016/j.immuni.2017.09.013

Miyake, Y., Tanaka, K., and Arakawa, M. (2013). Active and passive maternal smoking during pregnancy and birth outcomes: the Kyushu Okinawa maternal and child health study. BMC Preg. Child. 13:157. doi: 10.1186/1471-2393-13157

Moran, J. R., Courtney, M. E., Orth, D. N., Vaughan, R., Coy, S., Mount, C. D., et al. (1983). Epidermal growth factor in human milk: daily production and diurnal variation during early lactation in mothers delivering at term and at premature gestation. J. Pediatr. 103, 402-405. doi: 10.1016/s0022-3476(83)80412-0

Murata, Y., Shimamura, T., and Hamuro, J. (2002). The polarization of Th1/Th2 balance is dependent on the intracellular thiol redox status of macrophages due to the distinctive cytokine production. Int. Immunol. 14, 201-212. doi: 10.1093/intimm/14.2.201

Murphy, S. K., Adigun, A., Huang, Z., Overcash, F., Wang, F., Jirtle, R. L., et al. (2012). Gender-specific methylation differences in relation to prenatal exposure to cigarette smoke. Gene 494, 36-43. doi: 10.1016/j.gene.2011.11.062

Napierala, M., Mazela, J., Merritt, T. A., and Florek, E. (2016). Tobacco smoking and breastfeeding: Effect on the lactation process, breast milk composition and infant development. A critical review. Environ. Res. 151, 321-338. doi: 10.1016/j.envres.2016.08.002

Ng, S. P., Conklin, D. J., Bhatnagar, A., Bolanowski, D. D., Lyon, J., and Zelikoff, J. T. (2009). Prenatal exposure to cigarette smoke induces diet- and sexdependent dyslipidemia and weight gain in adult murine offspring. Environ. Health Perspect. 117, 1042-1048. doi: 10.1289/ehp.0800193

Nishida, K., Brune, K. A., Putcha, N., Mandke, P., O’Neal, W. K., Shade, D., et al. (2017). Cigarette smoke disrupts monolayer integrity by altering epithelial cell-cell adhesion and cortical tension. Am. J. Physiol. Cell Mol. Physiol. 313, L581-L591. doi: 10.1152/ajplung.00074.2017

Noakes, P. S., Hale, J., Thomas, R., Lane, C., Devadason, S. G., and Prescott, S. L. (2006). Maternal smoking is associated with impaired neonatal toll-likereceptor-mediated immune responses. Eur. Respir. J. 28, 721-729. doi: 10.1183/ 09031936.06.00050206

Noakes, P. S., Holt, P. G., and Prescott, S. L. (2003). Maternal smoking in pregnancy alters neonatal cytokine responses. Allergy 58, 1053-1058. doi: 10.1034/j.13989995.2003.00290.x

O’Loughlin, E. V., Chung, M., Hollenberg, M., Hayden, J., Zahavi, I., and Gall, D. G. (1985). Effect of epidermal growth factor on ontogeny of the gastrointestinal tract. Am. J. Physiol. 249, G674-G678. doi: 10.1152/ajpgi.1985.249.6.G674

Opleta-Madsen, K., Meddings, J. B., and Gall, D. G. (1991). Epidermal Growth Factor and Postnatal Development of Intestinal Transport and Membrane Structure. Pediatr. Res. 30, 342-350. doi: 10.1203/00006450-199110000-00 010

Owili, P. O., Muga, M. A., and Kuo, H.-W. (2018). Gender Difference in the Association between Environmental Tobacco Smoke and Birth Weight in Africa. Int. J. Environ. Res. Public Health 15:1409. doi: 10.3390/ijerph15071409 Paul, T., Schumann, C., Rüdiger, S., Boeck, S., Heinemann, V., Kächele, V., et al. (2014). Cytokine regulation by epidermal growth factor receptor inhibitors and epidermal growth factor receptor inhibitor associated skin toxicity in cancer patients. Eur. J. Cancer 50, 1855-1863. doi: 10.1016/j.ejca.2014.04.026 
Primo, C. C., Ruela, P. B. F., Brotto, L. D., de, A., Garcia, T. R., Lima, E., et al. (2013). Effects of maternal nicotine on breastfeeding infants. Rev. Paul. Pediatr. 31, 392-397. doi: 10.1590/S0103-05822013000300018

Rauschert, S., Melton, P. E., Burdge, G., Craig, J. M., Godfrey, K. M., Holbrook, J. D., et al. (2019). Maternal Smoking During Pregnancy Induces Persistent Epigenetic Changes Into Adolescence, Independent of Postnatal Smoke Exposure and Is Associated With Cardiometabolic Risk. Front. Genet. 10:770. doi: 10.3389/fgene.2019.00770

Rinaldi, M., Maes, K., De Vleeschauwer, S., Thomas, D., Verbeken, E. K., Decramer, M., et al. (2012). Long-term nose-only cigarette smoke exposure induces emphysema and mild skeletal muscle dysfunction in mice. Dis. Model. Amp. Mech. 5, 333-341. doi: 10.1242/dmm.008508

Robinson, K. M., Manni, M. L., Biswas, P. S., and Alcorn, J. F. (2013). Clinical consequences of targeting IL-17 and TH17 in autoimmune and allergic disorders. Curr. Allergy Asthma Rep. 13, 587-595. doi: 10.1007/s11882-0130361-0

Roy, P., Kumar, A., Kaur, I. R., and Faridi, M. M. A. (2014). Gender differences in outcomes of low birth weight and preterm neonates: the male disadvantage. J. Trop. Pediatr. 60, 480-481. doi: 10.1093/tropej/fmu042

Sabra, S., Gratacós, E., and Gómez Roig, M. D. (2017). Smoking-Induced Changes in the Maternal Immune, Endocrine, and Metabolic Pathways and Their Impact on Fetal Growth: A Topical Review. Fetal. Diagn Ther. 41, 241-250. doi: 10. $1159 / 000457123$

Sacks, G. P., Studena, K., Sargent, I. L., and Redman, C. W. G. (1998). Normal pregnancy and preeclampsia both produce inflammatory changes in peripheral blood leukocytes akin to those of sepsis. Am. J. Obstet. Gynecol. 179, 80-86. doi: 10.1016/S0002-9378(98)70254-6

Shahid, A., Lone, K. P., Saeed, S., and Arslan, M. (2008). Male offspring of both diabetic parents have higher insulin resistance and serum leptin levels compared to those with one diabetic parent. Hormones 7, 313-319. doi: 10. 14310/horm.2002.1212

Shamir, E. R., and Ewald, A. J. (2015). Adhesion in mammary development: novel roles for E-cadherin in individual and collective cell migration. Curr. Top. Dev. Biol. 112, 353-382. doi: 10.1016/bs.ctdb.2014.12.001

Shaykhiev, R., Zuo, W.-L., Chao, I., Fukui, T., Witover, B., Brekman, A., et al. (2013). shifts human airway basal cell fate toward a smoking-associated airway epithelial phenotype. Proc. Natl. Acad. Sci. U S A 110, 12102-12107. doi: 10. 1073/pnas. 1303058110

Shim, J. J., Dabbagh, K., Ueki, I. F., Dao-Pick, T., Burgel, P.-R., Takeyama, K., et al. (2001). 13 induces mucin production by stimulating epidermal growth factor receptors and by activating neutrophils. Am. J. Physiol. Cell Mol. Physiol. 280, L134-L140. doi: 10.1152/ajplung.2001.280.1.L134

Sopori, M. (2002). Effects of cigarette smoke on the immune system. Nat. Rev. Immunol. 2, 372-377. doi: 10.1038/nri803

Spinozzi, F., Agea, E., and de Benedictis, F. M. (2001). Are the intracellular cytokine profiles of cord blood T lymphocytes useful in detecting a high risk of asthma in the newborn? Pediatr. Allergy Immunol. Off. Publ Eur. Soc. Pediatr. Allergy Immunol. 12, 231-232. doi: 10.1034/j.1399-3038.2001.01094.x

Sporn, M. B., and Roberts, A. B. (1986). Peptide growth factors and inflammation, tissue repair, and cancer. J. Clin. Invest. 78, 329-332. doi: 10.1172/JCI112580

Stevenson, D. K., Verter, J., Fanaroff, A. A., Oh, W., Ehrenkranz, R. A., Shankaran, S., et al. (2000). Sex differences in outcomes of very low birthweight infants: the newborn male disadvantage. Arch. Dis. Child Fetal. Neonatal. Ed. 83, F182-F185. doi: 10.1136/fn.83.3.f182

Takahashi, K., Hirose, K., Kawashima, S., Niwa, Y., Wakashin, H., Iwata, A., et al. (2011). IL-22 attenuates IL-25 production by lung epithelial cells and inhibits antigen-induced eosinophilic airway inflammation. J. Allergy Clin. Immunol. 128, 1066-1067. doi: 10.1016/j.jaci.2011.06.018

Thébaud, B., and Abman, S. H. (2007). Bronchopulmonary dysplasia: where have all the vessels gone? Roles of angiogenic growth factors in chronic lung disease. Am. J. Respir. Crit. Care Med. 175, 978-985. doi: 10.1164/rccm.200611-1660PP

Uddin, M., Lau, L. C., Seumois, G., Vijayanand, P., Staples, K. J., Bagmane, D., et al. (2013). EGF-Induced Bronchial Epithelial Cells Drive Neutrophil Chemotactic and Anti-Apoptotic Activity in Asthma. PLoS One 8:e72502. doi: 10.1371/ journal.pone.0072502

Verheijden, K. A. T., Henricks, P. A. J., Redegeld, F. A., Garssen, J., and Folkerts, G. (2014). Measurement of airway function using invasive and non-invasive methods in mild and severe models for allergic airway inflammation in mice. Front. Pharmacol. 5:190. doi: 10.3389/fphar.2014.00190

Vestbo, J., and Hansen, E. F. (2001). Airway hyperresponsiveness and COPD mortality. Thorax 56, 11-14. doi: 10.1016/j.jaci.2016.04.022

Victoni, T., Gicquel, T., Bodin, A., Daude, M., Tenor, H., Valença, S., et al. (2016). Roflumilast n-oxide associated with PGE2 prevents the neutrophil elastaseinduced production of chemokines by epithelial cells. Int. Immunopharmacol. 30, 1-8. doi: 10.1016/j.intimp.2015.11.019

Wang, B., Chan, Y. L., Zhou, S., Saad, S., Chen, H., and Oliver, B. G. (2020). Offspring sex affects the susceptibility to maternal smoking-induced lung inflammation and the effect of maternal antioxidant supplementation in mice. J. Inflamm. 17:24. doi: 10.1186/s12950-020-00253-5

Wang, L., Mamudu, H. M., Collins, C., and Wang, Y. (2017). High prevalence of tobacco use and exposure to secondhand tobacco smoke among adolescents in low- and middle-income countries. Ann. Transl. Med. 5, S4-S4. doi: 10.21037/ atm.2017.03.37

Wang, Y., Gu, Y., Philibert, L., and Lucas, M. J. (2001). Neutrophil Activation Induced by Placental Factors in Normal and Pre-eclamptic Pregnancies In Vitro. Placenta 22, 560-565. doi: 10.1053/plac.2001.0691

Wang, Y.-H., and Liu, Y.-J. (2008). The IL-17 cytokine family and their role in allergic inflammation. Curr. Opin. Immunol. 20, 697-702. doi: 10.1016/j.coi. 2008.09.004

Wannamethee, S. G., Lowe, G. D. O., Shaper, A. G., Rumley, A., Lennon, L., and Whincup, P. H. (2005). Associations between cigarette smoking, pipe/cigar smoking, and smoking cessation, and haemostatic and inflammatory markers for cardiovascular disease. Eur. Heart J. 26, 1765-1773. doi: 10.1093/eurheartj/ ehi183

Xi, W., Renling, W., Tianling, H., and Fang, C. (2000). Effects of cigarette smoke extract on E-cadherin expression in cultured airway epithelial cells. J. Tongji. Med. Univ. 20, 32-35. doi: 10.1007/BF02887670

$\mathrm{Xu}, \mathrm{X}$., Su, Y., and Fan, Z. H. (2014). Cotinine concentration in serum correlates with tobacco smoke-induced emphysema in mice. Sci. Rep. 4:3864. doi: 10.1038/ srep03864

Zacharasiewicz, A. (2016). Maternal smoking in pregnancy and its influence on childhood asthma. ERJ Open Res. 2, 42-2016. doi: 10.1183/23120541.000422016

Zeboudj, L., Maître, M., Guyonnet, L., Laurans, L., Joffre, J., Lemarie, J., et al. (2018). Selective EGF-Receptor Inhibition in CD4+ T Cells Induces Anergy and Limits Atherosclerosis. J. Am. Coll. Cardiol. 71, 160-172. doi: 10.1016/j. jacc.2017.10.084

Zhao, Y., Yang, J., Gao, Y., and Guo, W. (2010). Th17 Immunity in Patients with Allergic Asthma. Int. Arch. Allergy Immunol. 151, 297-307. doi: 10.1159/ 000250438

Zuo, L., Li, Y., Wang, H., Wu, R., Zhu, W., Zhang, W., et al. (2014). Cigarette smoking is associated with intestinal barrier dysfunction in the small intestine but not in the large intestine of mice. J. Crohn's Colitis 8, 1710-1722. doi: 10.1016/j.crohns.2014.08.008

Conflict of Interest: JG and JB are employees of Danone Nutricia Research.

The remaining authors declare that the research was conducted in the absence of any commercial or financial relationships that could be construed as a potential conflict of interest.

Publisher's Note: All claims expressed in this article are solely those of the authors and do not necessarily represent those of their affiliated organizations, or those of the publisher, the editors and the reviewers. Any product that may be evaluated in this article, or claim that may be made by its manufacturer, is not guaranteed or endorsed by the publisher.

Copyright (C) 2021 Janbazacyabar, van Daal, Leusink-Muis, van Ark, Garssen, Folkerts, van Bergenhenegouwen and Braber. This is an open-access article distributed under the terms of the Creative Commons Attribution License (CC BY). The use, distribution or reproduction in other forums is permitted, provided the original author(s) and the copyright owner(s) are credited and that the original publication in this journal is cited, in accordance with accepted academic practice. No use, distribution or reproduction is permitted which does not comply with these terms. 